\title{
BACTEROIDES FRAGILIS IN SEPSIS
}

\section{Sugumari Chandrasegaran ${ }^{1}$}

${ }^{1}$ Senior Assistant Professor, Department of Microbiology, Madurai Medical College, Madurai.

\section{ABSTRACT}

\section{PURPOSE}

1. To find out the prevalence of Bacteroides fragilis in patients with Sepsis and to perform Antimicrobial susceptibility testing. 2. To identify the Metronidazole resistant Bacteroides fragilis and to confirm the resistant pattern genomically by gene sequencing.

\section{MATERIALS AND METHODS}

This prospective study was conducted for 6 months in 175 patients with varied infections. The presumptive identification of Bacteroides fragilis was confirmed and Antimicrobial susceptibility testing was performed by Broth disc method described by Kurynski \& Co-workers. Resistant strains confirmed by short sequencing by NCBI Blast.

\section{RESULTS}

Bacteroides fragilis was isolated from 32 of 175 samples with a prevalence of $18.3 \%$. Out of this 32 samples, only one organism revealed resistance to Metronidazole.

\section{CONCLUSION}

The prevalence of Bacteroides fragilis resistant to metronidazole was isolated in post-operative wound infections giving a warning signal to the clinicians on emerging Metronidazole resistance on nosocomial infections in this hospital.

\section{KEYWORDS}

Pus Samples, Bacteroides Fragilis, Metronidazole, Gene Sequencing.

HOW TO CITE THIS ARTICLE: Chandrasegaran S. Bacteroides fragilis in sepsis. J. Evolution Med. Dent. Sci. 2016;5(56):3847-3851, DOI: $10.14260 /$ jemds/2016/881

\section{INTRODUCTION}

The anaerobic Gram negative bacilli that make up the genus Bacteroides are among the most important constituents of the normal human flora and are plentiful in the oral cavity, GIT and the vagina. ${ }^{1}$ At one time the genus Bacteroides consisted of almost 50 species, but many of the species have now been transferred to new genera. The genus Bacteroides now consists of species previously categorized into the Bacteroides fragilis group and some closely related species.

Among the common infections caused by these bacteria are periodontal disease, post aspiration pleuropulmonary infection. $^{2}$ genital tract infection in women. ${ }^{3}$ and intraabdominal abscesses. ${ }^{4}$ CNS infections like brain abscesses and rarely meningitis.5,6 bacteremia.7,8 bone and joint infections.9,10 and skin and soft tissue infections such as diabetic.11,12 and decubitus ulcers. Cutaneous abscess below the waist have often been found to be caused by colonic flora anaerobes including Bacteroides fragilis.

These bacteria are identified presumptively on the basis of colony morphology, Gram staining characteristics, pigment production, susceptibility to special strength antibiotic disc and biochemical tests. Definitive identification requires multiple biochemical tests which are tedious to perform and because of expense not feasible for most clinical laboratories. Because of its clinical importance and relative antimicrobial

Financial or Other, Competing Interest: None.

Submission 06-06-2016, Peer Review 30-06-2016,

Acceptance 07-07-2016, Published 13-07-2016.

Corresponding Author:

Dr. Sugumari Chandrasegaran,

\#A 54, Santhinikethan Apartments,

Anna Nagar, Madurai-625020.

E-mail: doctorsugumari@yahoo.com

DOI: $10.14260 /$ jemds $/ 2016 / 881$ resistance, identification of Bacteroides fragilis is essential. Bacteroides fragilis group can be distinguished from other species of anaerobic Gram negative bacilli by growth in $20 \%$ bile. ${ }^{13}$ and resistance to special strength antibiotic disc. ${ }^{14}$ like kanamycin, vancomycin and colistin.

The medically important Bacteroides species are typically resistant to penicillin. Treatment failure with penicillin or first generation cephalosporins is common for infections that involve Bacteroides fragilis. Metronidazole, a 5-nitroimidazole derivative, is the drug of choice for treatment of Bacteroides infection. ${ }^{15}$ as resistance is rarely reported.

Fortunately enough, incidence of resistance to Metronidazole remains low $(<5 \%) .{ }^{16}$ A major contributing factor in the emergence of Metronidazole resistant Bacteroides species is the acquisition and transfer of antibiotic resistance via chromosomal or on mobilisable plasmids. ${ }^{17,18}$

The DNA sequencing of the purified PCR product. ${ }^{18,19}$ is shown to be an useful method to find out resistance genes, which are found to be 'nim' resistance genes. ${ }^{20,21}$

\section{MATERIALS AND METHODS \\ Settings}

This prospective study was conducted in a tertiary care hospital in Madurai, located in the Southern part of India. DNA isolation was carried out at the Department of Immunology, at a parallel research facility in Madurai. The PCR was carried out in yet another research facility under the Madurai Kamaraj University in the Applied Biosystem Gene (ABG) Amp PCR 2700 .

\section{Study Period}

The study conducted for 6 months from February-July 2015.

\section{Sample Size}

The study population consisted of 175 patients with varied infections admitted in different wards. 


\section{Inclusion Criteria}

Newly admitted patients with varied infections without antibiotic treatment.

\section{Exclusion Criteria}

Patients admitted with varied infections on antibiotic treatment and with other chronic infections.

\section{Specimen Collection}

Liquid thioglycollate medium was used for both collection and transport of specimens for anaerobic incubation and glucose broth for aerobic organisms. Special precautions were taken to protect the specimens thus collected from the lethal effects of atmospheric oxygen right from the collection till their incubation in the laboratory.

\section{Processing}

Gram staining was done and microscopic findings noted. After 24-48 hours of incubation, both aerobic and anaerobic samples were inspected for turbidity, odour and purulence. A combination of enriched, selective, non-selective plating media were used for the primary isolation and presumptive identification of obligate anaerobes from the clinical material. Direct plating was done in the blood agar and bile esculin agar with kanamycin plating media and incubated in a Gaspak anaerobic jar for 48 hours at $37^{\circ} \mathrm{C}$. After 48 hours of incubation the plates were examined for colony growth, morphology and haemolysis pattern, susceptibility to special potency discs. These suspected colonies were subjected to spot indole test and catalase test and later tested for fermentation of sugars for confirmation of species.

\section{Interpretation}

Grey white, glistening, non-haemolytic colonies, pale irregular staining, Gram negative, pleomorphic rods, resistant to all 3 special potency antibiotic discs, Spot Indole negative and Catalase positive fermenting sucrose and not fermenting arabinose were considered as Bacteroides fragilis and subjected for antimicrobial susceptibility testing for anaerobes. The broth disc test described by Kurynski and Coworkers was followed.

All the metronidazole resistant isolates were selected and subjected for DNA isolation, which was amplified by PCR method and amplified product was subjected for gene sequencing. Short sequencing, i.e. upto $600 \mathrm{bp}$ of the amplified DNA was done commercially. The 16S rDNA homology analysis for metronidazole sensitive and resistant strains of Bacteroides fragilis was done using NCBI Blast.

\section{RESULTS}

Out of the 175 samples collected, more number of samples were from the post-operative wound infections followed by diabetic foot ulcers in General Surgical ward.

Table 1 shows that there were more number of Gram negative isolates, 149 samples (85.1\%). Out of the 149 , Gram negative isolates, 117 (78.6\%) were aerobes and 32 (21.4\%) were anaerobes.

\begin{tabular}{|c|c|c|c|}
\hline $\begin{array}{l}\text { Sl. } \\
\text { No. }\end{array}$ & \multicolumn{2}{|c|}{ Gram Reaction } & $\begin{array}{l}\text { Number of } \\
\text { Isolates }\end{array}$ \\
\hline \multirow{3}{*}{1} & $\begin{array}{l}\text { Gram Negative } \\
(149)(85.1 \%)\end{array}$ & Aerobes & $117(78.6 \%)$ \\
\hline & & Anaerobes & $32(21.4 \%)$ \\
\hline & Total & & $149(85.1 \%)$ \\
\hline \multirow{3}{*}{2} & $\begin{array}{l}\text { Gram Positive } \\
\text { (26) }(14.9 \%)\end{array}$ & Aerobes & $26(100 \%)$ \\
\hline & & Anaerobes & $0(0 \%)$ \\
\hline & Total $(n=175)$ & & $26(100 \%)$ \\
\hline
\end{tabular}

Table 1: Aerobes, Anaerobes Vs Primary Gram Reaction

As Bacteroides fragilis is the common Gram negative anaerobe from wound infections, all the 32 Gram negative anaerobes were analysed.

\begin{tabular}{|c|c|c|}
\hline $\begin{array}{c}\text { Sl. } \\
\text { No. }\end{array}$ & Specimens & $\begin{array}{c}\text { Number of } \\
\text { Isolates }\end{array}$ \\
\hline 1 & Pus & $28(21 \%)$ \\
\hline 2 & Blood & $2(10 \%)$ \\
\hline 3 & Aspirate & $2(9 \%)$ \\
\hline \multicolumn{3}{|c|}{ Table 2: Specimen Wise Distribution } \\
of Bacteroides Fragilis \\
\hline \multicolumn{2}{|c|}{} \\
\hline
\end{tabular}

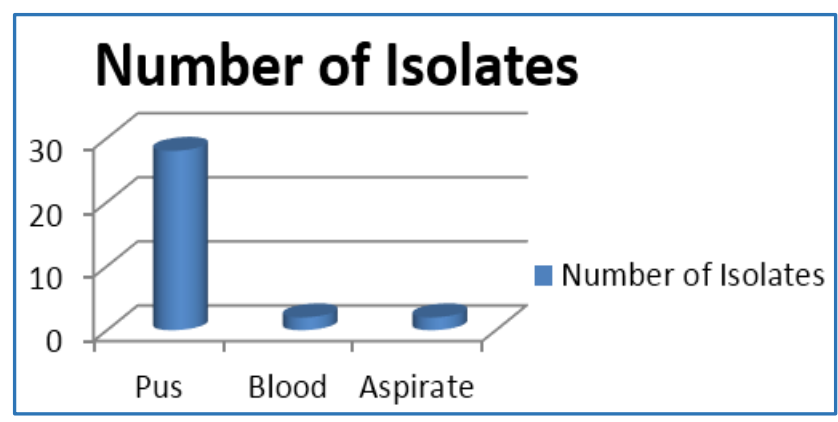

Chart 1: Specimen Wise Distribution of Bacteroides Fragilis

Table 2 (Chart 1) shows that out of the total 32 Bacteroides fragilis, 28 (21\%) were isolated from pus, 2 (10\%) were isolated from blood and $2(9 \%)$ were isolated from aspirates. Thus maximum recovery of Bacteroides fragilis isolates were from pus (21\%), and less number of isolates were from blood and aspirates.

\begin{tabular}{|c|c|c|}
\hline $\begin{array}{c}\text { Sl. } \\
\text { No. }\end{array}$ & $\begin{array}{c}\text { Name of the } \\
\text { Ward }\end{array}$ & $\begin{array}{c}\text { No. of Isolates } \\
\text { of Bacteroides } \\
\text { Fragilis }\end{array}$ \\
\hline 1 & General Surgery & $18(10.2 \%)$ \\
\hline 2 & Burns & $5(2.8 \%)$ \\
\hline 3 & Orthopaedics & $3(1.7 \%)$ \\
\hline 4 & $\begin{array}{c}\text { Obstetrics and } \\
\text { Gynaecology }\end{array}$ & $3(1.7 \%)$ \\
\hline 5 & $\begin{array}{c}\text { Surgical } \\
\text { Gastroenterology }\end{array}$ & $3(1.7 \%)$ \\
\hline \multicolumn{2}{|c|}{ Total (n=32) } & $\mathbf{3 2}(18.2 \%)$ \\
\hline \multicolumn{2}{|c|}{ Table 3: Ward Wise Distribution of Bacteroides Fragilis } \\
\hline
\end{tabular}




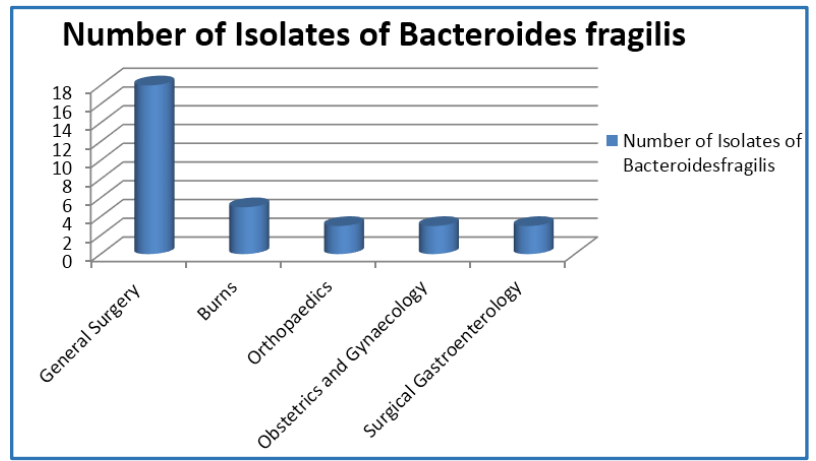

Chart 2: Ward Wise Distribution of Bacteroides Fragilis

Table 3 (Chart 2) shows that out of the total 32 (18.2\%) Bacteroides fragilis isolated, 18 (10.2\%) were from General Surgery ward, 5 (2.8\%) were isolated from Burns ward, 3 $(1.7 \%)$ were isolated from Orthopaedics, Surgical Gastroenterology and Obstetrics and Gynaecology wards each. Thus, it was found that more number of Bacteroides fragilis were isolated from General Surgery wards (10.2\%), then the Burns ward (2.8\%) and all the other wards showed less number of isolates.

\begin{tabular}{|c|c|c|}
\hline $\begin{array}{c}\text { Sl. } \\
\text { No. }\end{array}$ & Clinical Conditions & $\begin{array}{c}\text { Number of } \\
\text { Isolates }\end{array}$ \\
\hline 1 & $\begin{array}{c}\text { Post-Operative } \\
\text { Wound Infections }\end{array}$ & $14(8 \%)$ \\
\hline 2 & $\begin{array}{c}\text { Wound Infections } \\
\text { Following Burns }\end{array}$ & $2(1.1 \%)$ \\
\hline 3 & Diabetic Foot Ulcers & $11(6.2 \%)$ \\
\hline 4 & $\begin{array}{c}\text { Open Injury } \\
\text { Following Accidents }\end{array}$ & $2(1.1 \%)$ \\
\hline 5 & Decubitus Ulcers & $1(0.5 \%)$ \\
\hline 6 & Septicaemia & $1(0.5 \%)$ \\
\hline 7 & $\begin{array}{c}\text { Intra-abdominal } \\
\text { Abscesses }\end{array}$ & $1(0.5 \%)$ \\
\hline \multicolumn{2}{|c|}{ Total (n=32) } & 3able 4: Distribution of Bacteroides \\
\multicolumn{2}{|c|}{ Fragilis Vs Clinical Conditions } \\
\hline
\end{tabular}

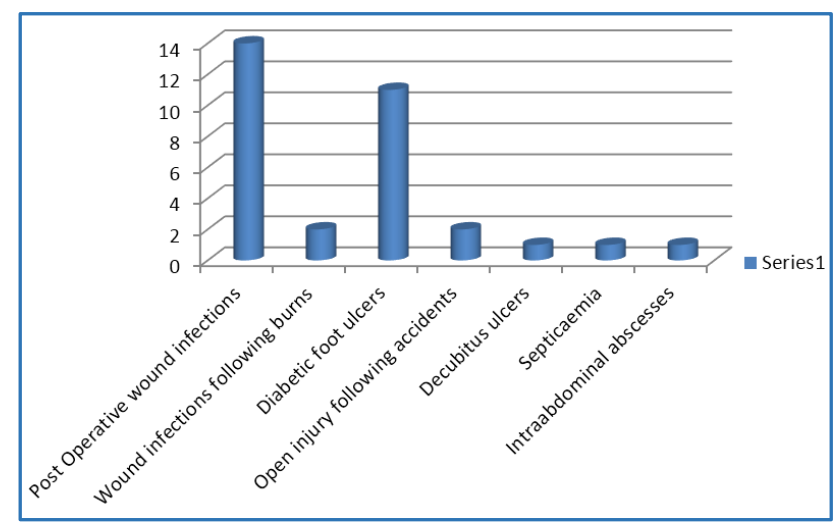

Chart 3: Distribution of Bacteroides Fragilis Vs Clinical Conditions

Table 4 (Chart 3) shows that out of the total 32 isolates, 14 $(8 \%)$ were isolated from post-operative wound infections, 11 $(6.2 \%)$ isolated from diabetic foot ulcers, $2(1.1 \%)$ isolates were from wound infections following Burns, 2 (1.1\%) were from open injury following accidents, $1(0.5 \%)$ was isolated from decubitus ulcers, septicaemia and intra-abdominal abscess each. It was found that more number of isolates were from post-operative wound infections (8\%) than the diabetic foot ulcers (6.2\%), equal number of isolates from burns and open injury following accidents and least number from other infections.

\begin{tabular}{|c|c|c|c|}
\hline $\begin{array}{c}\text { Sl. } \\
\text { No. }\end{array}$ & Drugs & $\begin{array}{c}\text { Total } \\
\text { Number } \\
\text { Sensitive (\%) }\end{array}$ & $\begin{array}{c}\text { Total } \\
\text { Number } \\
\text { Resistant (\%) }\end{array}$ \\
\hline 1 & Carbenicillin & $28(87.5 \%)$ & $4(12.5 \%)$ \\
\hline 2 & Cefoperazone & $29(90.7 \%)$ & $3(9.3 \%)$ \\
\hline 3 & Chloramphenicol & $31(96.9 \%)$ & $1(3.1 \%)$ \\
\hline 4 & Clindamycin & $28(87.5 \%)$ & $4(12.5 \%)$ \\
\hline 5 & Metronidazole & $31(96.9 \%)$ & $\mathbf{1}(3.1 \%)$ \\
\hline 6 & Penicillin G & $26(81.2 \%)$ & $6(18.8 \%)$ \\
\hline 7 & Cefotaxime & $30(93.8 \%)$ & $2(6.2 \%)$ \\
\hline 8 & Tetracycline & $29(90.7 \%)$ & $3(9.3 \%)$ \\
\hline \multicolumn{3}{|c|}{ Table 5: Antimicrobial Susceptibility Testing } \\
\hline
\end{tabular}

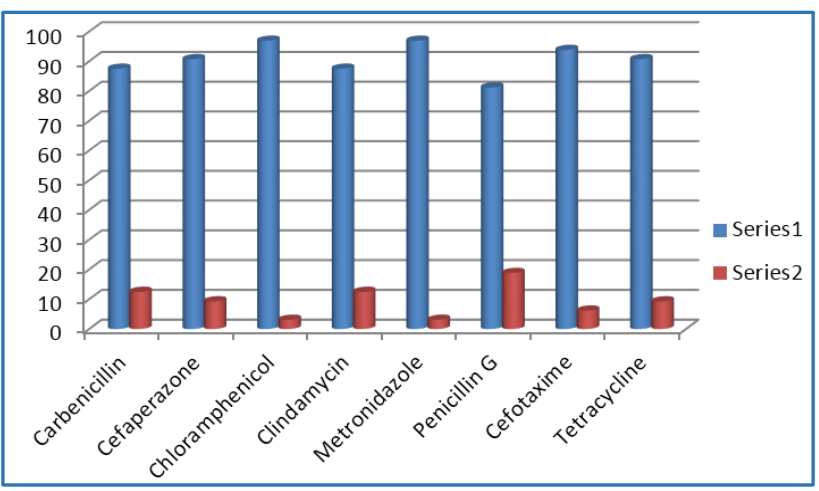

Chart 4: Antimicrobial Susceptibility Testing

Table 5 (Chart 4) shows that out of the 32 isolates, 28 $(87.5 \%)$ were susceptible and $4(12.5 \%)$ were resistant for carbenicillin, $29(90.7 \%)$ susceptible and $3(9.3 \%)$ resistant for cefoperazone, 31 (96.9\%) sensitive and 1 (3.1\%) resistant for chloramphenicol, $28(87.5 \%)$ sensitive and $4(12.5 \%)$ resistant for clindamycin, $31(96.9 \%)$ sensitive and 1 (3.1\%) resistant for metronidazole and $26(81.2 \%)$ susceptible and 6 (18.8\%) resistant for penicillin, 30 (93.8\%) susceptible and 2 (6.2\%) resistant for cefotaxime, $29(90.7 \%)$ susceptible and 3 (9.3\%) resistant for tetracycline. Thus, it was found that only one organism was resistant for metronidazole and chloramphenicol, i.e. $3.1 \%$ each which was also sensitive to clindamycin and all the other antimicrobials showed resistance more than $6 \%$.

The DNA of the Metronidazole resistant Bacteroides fragilis and the one Metronidazole sensitive Bacteroides fragilis were amplified by PCR and the amplified DNA was subjected for DNA short sequencing, which were analysed by comparison of $16 \mathrm{~S}$ rDNA sequences with the GenBank sequence by using the Basic Local Alignment Search Tool (BLAST).

\section{THE SEQUENCE IS GIVEN AS FOLLOWS}

Metronidazole Sensitive Bacteroides Fragilis 16s rDNA Sequence

\begin{tabular}{|l|} 
agagtttgatcctngctcaggatnaacgctagctacaggcttaacacatgcaagtcgagg \\
ggcatcaggaagaaagcttgctttctttgctggngaccggcgcacgggtgagtaacacgt \\
atccaaccngccctttactcgggnatagccttcgaaagaaagattaatacccgatagca \\
taatgatnccgcatggtttcattantaaaggattcnggtaaaggatggggatncgttcca \\
ttaggttgttggngaggtaacggcccaccaagccttngatggataggggttctgagagga \\
aggtccccnacattggaactgagacacggtccaaactcntacgggaggcagcaatcgaat \\
tncg
\end{tabular}




\section{Metronidazole Resistant Bacteroides Fragilis 16s rDNA Sequence}

agagtttgancctngctcacgattaacgctagctacaggcttaacacatgcaagtcgagg
ggcatcaggaagaaagcttgctttctttgctggcgaccggcgcacgggtgagtaacaggt
atccaaccngcccttnactcgggnatagtctttcgaaagaaagattaatacccgatagca
taatnatnccgcatggtatcattantaaaggattcnggtaaaggatggggatncgttcca
ttaggttgttggngaggtagcggcncaccaagtcttngatggataggggttctgagagga
aggtcccnacattggaagtgagncacggtccaaactcntatgggaggcagcaatcgaat
tncg

The homology analysis between the sensitive and resistance strains showed a difference of only $2.4 \%$ between them establishing them as separate strains.

\section{DISCUSSION}

Anaerobes are increasingly recognized as important pathogens in post-operative wound infections, deep seated abscesses, burns, etc. Metronidazole is the drug of choice in treating anaerobic infections. Bacteroides fragilis is one important anaerobe, in which there is emerging resistance to metronidazole. Hence, this study on Bacteroides fragilis in Sepsis was aimed at finding the Gram negative anaerobe, Bacteroides fragilis which are metronidazole resistant and to find the gene sequencing of the resistant strain. The highest number of the cases of sepsis were found in the General Surgical ward (38.2\%), where the post-operative wound infection was the most essential problem. Anielski et $\mathrm{al}^{22}$ in their study on wound infection also revealed that the postoperative wound infection in surgical ward was very common.

In the present study, the common specimen collected for the analysis of Bacteroides fragilis were pus (76\%), the wound aspirate $(12.6 \%)$ and the blood (11.4\%). Most of the pus samples were from the deep abscesses and aspirates were from the deep wounds and blood were from the septic cases. The study by Cruse $\mathrm{P}$ et $\mathrm{al}^{23}$ about wound infection surveillance demonstrated that most of the anaerobic species of organisms were isolated from abscesses and were mostly polymicrobial. Among the anaerobes, Bacteroides species were common. In the present study, $85.1 \%$ of the samples showed Gram negative organisms and 14.9\% showed Gram positive organisms which gives the ratio of $5: 1$. This is supported by the study of Oni A A et al $^{24}$ in which they showed the ratio of Gram negative-to-Gram positive to be 4.6:1. In the present study it was shown that Bacteroides fragilis was the common Gram negative organism isolated from wound infections (18.2\%), especially from the Surgery ward (10.2\%). Appelbaum et $\mathrm{al}^{25}$ also demonstrated Bacteroides fragilis as the common Gram negative anaerobe in $15.8 \%$ of their specimens.

In the present study it was shown that out of 133 pus samples, Bacteroides fragilis was isolated from 28 (21\%) and Bacteroides fragilis was isolated from $2(10 \%)$ out of 20 blood samples and from 2 (9\%) out of 22 aspirate samples. Thus Bacteroides fragilis was commonly isolated from pus samples, especially from General Surgical wards followed by blood samples and the aspirates. Bowler PG et $\mathrm{al}^{3}$ in his article explained a wide variety of virulent factors in Bacteroides fragilis, which were responsible for wound infections.

The antimicrobial susceptibility testing of Bacteroides fragilis in the present study have shown that Bacteroides fragilis was sensitive to the Metronidazole (96.8\%) and resistant to 3.1\% to Chloramphenicol and Metronidazole. Soki J et al26, Stubbs et al27, Trinhs and Reysset et al ${ }^{28}$. Jamal W Y et $\mathrm{al}^{29}$ had shown Metronidazole resistant Bacteroides fragilis which are in support of our study.

The sequence analysis by short sequencing method done, revealed that the $16 \mathrm{Sr}$ DNA sequence was approximately $99 \%$ homology to Bacteroides fragilis genome. This establishes beyond doubt that biochemically proved strain is indeed Bacteroides fragilis. Similar study by Jeffrey M Schapiro et al ${ }^{30}$ also showed the confirmation of the identity of Bacteroides fragilis by sequencing of $16 \mathrm{~S}$ rDNA. This establishes beyond doubt that biochemically proved strain is indeed Bacteroides fragilis. The same study also showed the confirmation of the identity of Bacteroides fragilis by sequencing of $16 \mathrm{~S}$ rDNA.

The homology analysis between Metronidazole sensitive Bacteroides fragilis and Metronidazole resistant Bacteroides fragilis showed a difference of $2.4 \%$ denoting that they are separate strains. Similar study by Yuli Song et $\mathrm{al}^{31}$ in his study on the evaluation of $16 \mathrm{Sr}$ DNA in the clinical identification of Bacteroides species revealed that if an isolate showed genetic difference of $>1 \%$ and $<2 \%$ that was closely related to its best match. Thus, he proved that 21 of his isolates had $98.6 \%$ sequencing similarity. In the present study the genetic difference was more than $2 \%$, hence it is confirmed that both the strains are different.

\section{CONCLUSION}

Bacteroides fragilis has emerged out as an important anaerobic organism contributing to infections in surgical wards. Among them, resistance to metronidazole was also observed.

The present study on Bacteroides fragilis in Sepsis was attempted to find out the prevalence of Bacteroides fragilis and to perform antimicrobial profile of these organisms in order to segregate metronidazole resistant samples from others and process the same for gene sequencing. Finally, it was proposed to give guidelines to clinicians dealing with such cases of pyogenic infections.

Bacteroides fragilis was isolated from 32 out of 175 samples and the prevalence was $18.3 \%$. The isolates were more from post-operative wound infections, which constituted $8 \%$. The isolates were more from males (M:F=2:1) and it was attributed to their behaviour.

Many of the isolates were resistant to multidrugs, but only one of them was resistant to metronidazole. This resistant isolate along with a metronidazole sensitive isolate were subjected to genomic sequencing. The homology of the resistant strain was different by $2.4 \%$ with the sensitive strain, thus confirming the resistance pattern genomically.

In view of the emerging multidrug resistance pattern among Bacteroides fragilis, the clinicians were informed about the pattern of resistance and the need for polyantimicrobial therapy in deserving cases on clinical and laboratory grounds. In view of the emerging infections, surgeons were informed about the inclusion of clindamycin in the management of postoperative wound infection.

\section{REFERENCES}

1. Evaldson G, Heindahl A, Kager L, et al. The normal human anaerobic micro flora. Scandinavian Journal of infect Diseases 1982;35:(9-15). 
2. De A, Varaiya A, Mathur M. Anaerobes in pleuro pulmonary infections. IJMM 2002;20(3):150-2.

3. Shapiro M, Munoz A, Tager IB, et al. Risk factors for infection at the operative site after abdominal or vaginal hysterectomy. N Engl J Med 1982;307(27):1661-6.

4. Dunn DL, Simmons RL. The role of anaerobic bacteria in intra-abdominal infections. Reviews of Infectious Diseases 1984;6(Suppl 1):139-46.

5. Das P, De A, Sharma A. Bacteriology of intracranial abscesses with special reference to anaerobes. IJMM 2000;18(4):184-8.

6. Gupta U. A study of bacteroidaceae from clinical material. Indian J Med Res 1973;61(7):1002-8.

7. Felner JM, Dowell VR. Bacteroides bacteraemia. Am J Med 1971;50(6):787-96.

8. Alridge KE, Ashcraft D, O'Brien M, et al. Bacteraemia due to bacteroides fragilis group; distribution of species, $\beta$ lactamase production and antimicrobial susceptibility patterns. Antimicrob agents chemotherap 2003;47(1):148-53.

9. Bowler PG, Duerden BI, Armstrong DG. Wound microbiology and associated approaches to wound management. Clinical Microbiology Reviews 2001;14(2):244-69.

10. Hall WL, Sobel AI, Jones CP. Anaerobic postoperative pelvic infections. Obst Gynaecol 1967;30(1):1-7.

11. Amalia CS, Colayco MD, Mendoza MT, et al. Microbiologic and clinical profile of anaerobic diabetic foot infections. Phil J Microbiol Infect Disease 2002;31(4):151-60.

12. Louie TJ, Barlett JG, Tally FP. Aerobic and anaerobic bacteria in diabetic foot ulcers. Ann Intern Med 1976:85(4):461-3.

13. Weinberg LG, Smith LL, McTighe AH. Rapid identification of the bacteroides fragilis group by bile disc and catalase tests. Laboratory medicine 1983;14:785-8.

14. Draper DL, Barry AL. Rapid identification of bacteroides fragilis with bile and antibiotic disks. J Clin Microbiol 1977;5(4):439-43.

15. Shimada K, Inamatsu T, Sato K. Bacteriological and clinical studies on metronidazole in bacteroides fragilis infections. Jpn J Antibiot 2004;32(2):191-4.

16. Chaudary R, Mathur P, Dhawan B, et al. Emergence of metronidazole resistant bacteroides fragilis, India. Emerging infect Diseases 2001;7(3):485-6.

17. Chaudhry R, Majumdar T. Dhawan-genus bacteroidesnewer concepts in pathogenesis and drug resistance. IJMM 1997;15(3):107-111.

18. Edlund C, Hedberg M, Nord CE, et al. New findings in betalactam and metronidazole resistant bacteroides fragilis group. Int J Antimicrob Agents 2002;19(5): 361-70.
19. Yamashita Y, Kohno S, Koga H. Detection of bacteroides fragilis in clinical specimens by PCR. J Clin Microbiol 1994;32(3):679-83.

20. Gal M, Brazier JS. Metronidazole resistance in bacteroides species carrying nim genes and the selection of slow growing metronidazole resistant mutants. J Antimicrobchemothera 2004;54(1):109-16.

21. Haggoud A, Hand RA, Reysset G. Prevalence and characteristics of nim genes encoding 5-nitroimidazole resistance among bacteroides strains isolated in morocco. Microbiol Drug Resist 2001;7(2):177-81.

22. Anielski R, Barczynski M. Postoperative wound infections II. risk factors related to surgery. Prezegl Lek 1998;55(3):109-19.

23. Cruse PJ, Foord R. The epidemiology of wound infection. A 10 year prospective study of 62,939 wounds. Surg Clin North Am 1980;60(1):27-40.

24. Oni AA, Bakare RA, Okesola AO, et al. Pattern of bacterial pathogens in surgical wound infections. Afr J Med Sci 1997;26(3-4):139-40.

25. Appelbaum PC, Holloway Y, Hallett AF. Anaerobic infections in hospital practice. S Afr Med J 1976;50(3F):1435-8.

26. Soki J, Gal M, Urban E, et al. Molecular investigation of genetic elements contributing to metronidazole resistance in bacteroides strains. J Antimicrob Chemother 2006;57(2):212-20.

27. Stubbs SL, Brazier JS, Talbot PR. PCR-restriction fragment length polymorphism analysis for identification of bacteroides spp and characterization of nitroimidazole resistance genes. J Clin Microbiol 2000;38(9):3209-13.

28. Trinh S, Reysset G. Detection by PCR of the nim genes encoding 5 nitroimidazole resistance in bacteroides spp. J Clin Microbiol 1966;34(9):2078-84.

29. Jamal WY, Rotimi VO, Brazier JS, et al. Molecular characterization of nitroimidazole resistance in metronidazole resistant bacteroides species isolated from hospital patients in Kuwait. Med Princ Pract 2004;13(3):147-52.

30. Schapiro JM, Gupta R, Stefansson E. Isolation of metronidazole resistant bacteroides fragilis carrying the nim a nitro reductase gene from a patient in Washington state. J Clini Microbiol 2004;42(9):4127-9.

31. Song Y, Liu C, Bolanos M, et al. Evaluation of $16 \mathrm{Sr}$ DNA sequencing and re-evaluation of short biochemical scheme for identification of chemically significant bacteroides species. J Clin Microbiol 2005;43(4):1531-7. 